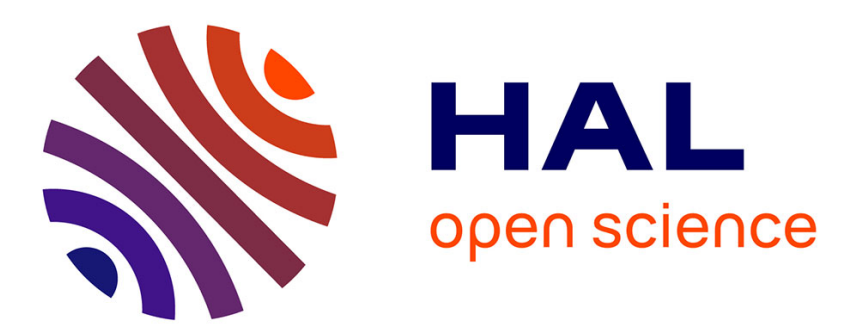

\title{
High-Strain, High-Strain-Rate Deformation Behavior of Tantalum and Tantalum-Tungsten Based Alloys
}

\author{
F. Marquis, Y. Chen
}

\section{To cite this version:}

F. Marquis, Y. Chen. High-Strain, High-Strain-Rate Deformation Behavior of Tantalum and Tantalum-Tungsten Based Alloys. Journal de Physique IV Proceedings, 1997, 07 (C3), pp.C3-441-C3446. 10.1051/jp4:1997376 . jpa-00255533

\section{HAL Id: jpa-00255533 https://hal.science/jpa-00255533}

Submitted on 1 Jan 1997

HAL is a multi-disciplinary open access archive for the deposit and dissemination of scientific research documents, whether they are published or not. The documents may come from teaching and research institutions in France or abroad, or from public or private research centers.
L'archive ouverte pluridisciplinaire HAL, est destinée au dépôt et à la diffusion de documents scientifiques de niveau recherche, publiés ou non, émanant des établissements d'enseignement et de recherche français ou étrangers, des laboratoires publics ou privés. 
J. PHYS IV FRANCE 7 (1997)

Colloque C3, Supplément au Journal de Physique III d'août 1997

\title{
High-Strain, High-Strain-Rate Deformation Behavior of Tantalum and Tantalum-Tungsten Based Alloys
}

\author{
F.D.S. Marquis and Y.J. Chen* \\ College of Materials Science and Engineering, South Dakota School of Mines \& Technology, \\ Rapid City, SD 57701, U.S.A. \\ * Department of Applied Mechanics and Engineering Sciences, University of California, \\ San Diego, La Jolla, CA 92093, U.S.A.
}

\begin{abstract}
Ahstract. The microstructural evolution in high-strain, high-strain-rate deformation of annealed tantalum and tantalum-tungsten alloys with 1 and $2.5 \mathrm{wt} . \%$ and the occurrence of shear localization has been investigated. The microstructure generated at high strain rates progresses from highly dislocated grains, to lath cells, to subgrains, and finally to small grains as the shear strain increases. The temperature rise predictions from the constitutive equations which describe the materials behavior indicate that the temperature reaches values which allow dynamic recovery, and approach and reach limited localized dynamic recrystallization. This is supported by observations of the microstructure in regions within and adjacent to the shear localization.

Résumé. Nous avons réalisé une étude systématique de l'évolution de la microstructure e de la localisation du cisaillement dans du tantale et des alliages du tantale avec wolfram à 1 et $2.5 \%$ en poids, déformés dans des conditions dynamiques jusqu'a des haut taux de déformation. L'évolution de la microstructure avec le niveau de deformation commence pour la formation des grains aux très haut densité de dislocations, et progress pour la creation de latte cellules, la formation de sous-grains, et finalement la creation des grains. Les équations constitutif du comportment des matériaux on permis une estimation des températures développés, en accord avec le recouvrement dynamique et le commencement de la recristalisation dynamique. Ce modèle est confirmé pour les observations en microscopie électronique en transmission (MET) faite en aire de la localisation du cisaillement.
\end{abstract}

\section{INTRODUCTION}

Due to their high density and ductility, tantalum and tantalum-based alloys are excellent materials for use in shaped charges and explosively-forged projectiles (EFP's). The plastic strains typically encountered in these applications are up to 10 in shaped charges and up to 5 in EFP's. Tantalum and tantalum-based alloys exhibit a high temperature and strain-rate sensitivity and their mechanical properties are highly affected by interstitial solutions. Armstrong et al [1] have attributed this behavior to the rate controlling mechanism of the thermal component of the flow stress.

A specific double-kink mechanism has been proposed by Seeger [2] and extended by Dorn and Rajrak [3]. Detailed analyses on the thermally activated plastic deformation in tantalum have been carried out by Gypen and Deruythere [4] (single crystals) and Werner [5] (solid solutions). Koizumi et al [6] calculated the effect of the barrier shape on the flow stress vs. temperature for a number of BCC including tantalum. The activation volume for BCC metals is much smaller than for FCC metals, yielding a much higher temperature and strain-rate sensitivity. This basic difference between the activation volumes of FCC and BCC metals has served as the basis for the Zerilli - Armstrong [7, 8] constitutive equations.

The constitutive behavior of tantalum has been studied by Bechtold [9], Gilbert et al [10], Mitchell and Spitzig [11], Mordike and Rudalf [12], and Hoge and Mukherjee [13]. More recently, the shock response of Ta has been explored by Lassila and Gray [14], Gurevitch et al [15] have reported evidence for recrystallization in recovered shaped-charge slags and jets. Meyers et al. [16] have also reported evidence of recovery and beginning of recrystallization in specimens subjected to high strain and high-strain rates.

The objective of this study is to characterize the microstructural evolution and to understand the underlying deformation mechanisms of tantalum and tantalum-tungsten based alloys subjected to high strains at high strain rates.

\section{MATERIALS}

The materials used in this investigation were produced and processed by Cabot Corporation. They were produced as disks with a diameter of $155 \mathrm{~mm}\left(6.1^{\prime \prime}\right)$ and thickness of $8 \mathrm{~mm}\left(0.31^{\prime \prime}\right)$ for Ta and $3.8 \mathrm{~mm}$ $\left(0.15^{\prime \prime}\right)$ for Ta-W alloys. These disks were obtained through press forging of $30 \mathrm{~cm}$-high ingots into $10 \mathrm{~cm}$ slabs. Subsequent to annealing, the slabs were cross-rolled to the final thickness $(8 \mathrm{~mm})$ with intermediate anneals. As a result of processing, the disks exhibited a texture which was determined through direct pole figures and orientation distribution function analysis [16]. The final rolling direction was designated the 
longitudinal direction [LD] and the direction in a plane at $90^{\circ}$ was designated the transverse direction [TD]. The texture of $\mathrm{Ta}$ and Ta-based alloys is known to significantly affect their deformation behavior. Feng and Kumar [17] and Clark et al $[18,19]$ investigated the effects of processing parameters on texture. It is also known that the performance of explosively forged projectiles is critically dependent on their texture.

\section{EXPERIMENTAL PROCEDURES}

Specimens were tested in compression and shear. Specimens were trepanned from the disk by electrodischarge machining. Compression specimens for quasi-static testing had dimensions of $4.83 \mathrm{~mm}$ diameter X $4.83 \mathrm{~mm}$ length. For dynamic testing, two types of specimens were tested in a split Hopkinson bar: conventional cylindrical compression specimens with $4.83 \mathrm{~mm}$ diameter $X 3.81 \mathrm{~mm}$ length, and especially designed disk specimens with $3 \mathrm{~mm}$ diameter X $0.4 \mathrm{~mm}$ thickness. The disk specimens were only used for recovery tests, since the frictional boundary conditions significantly affect the overall stress response. By the use of these thin disk specimens it was possible to impart true effective compressive strains of up to 1.23 .

Controlled shear experiments were carried out using the hat-shaped specimens developed by Meyer and Manwaring [20]. The techniques for the use of hat-shaped specimens are described by Meyers et al [21-22]. These techniques are designed for the application of controlled and prescribed levels of shear strain, at high strain rates, in regions subjected to a state of simple shear. The wave-trapping scheme developed by NematNasser and Isaacs [23] has two significant advantages: (a) it enables the establishment of prescribed and controlled shear strains; and (b) it eliminates unwanted reflections which can produce spurious straining of specimen.

Dynamic compression tests were carried out at a strain rate within the range $2-5 \times 10^{3} \mathrm{~s}^{-1}$ at ambient and elevated temperatures $\left(325\right.$ and $\left.525^{\circ} \mathrm{C}\right)$. High-strain rate tests were carried out at elevated temperatures in quasi-isothermal and adiabatic conditions using techniques developed by Isaacs and Nemat-Nasser [24].

Hat-shaped specimens were sliced along the length of the deformation band (from top to bottom). Typically 3 to 4 slices were obtained. These slices were then polished and etched to reveal the evolution of the microstructure along the deformation band. Then, in one slice, typically 3 to 4 discs $(\phi=3 \mathrm{~mm})$ were cut for TEM from specific areas of precisely measured strain. Electropolishing (using a solution of $93 \%$ methanol $+5 \%$ sulfuric acid $+2 \%$ hydrofluoric acid at $-40^{\circ} \mathrm{C}$ ) was followed, where necessary, by ion milling. In order to investigate and fully characterize typical microstructures optical, transmission electron microscopy (TEM) and electron diffraction with selected area diffraction patterns (SADP's) analysis were carried out.

\section{RESULTS AND DISCUSSION}

\subsection{Dynamic Compression Tests}

In order to determine the temperature evolution and the microstructure evolution under high-strain-rate deformation, compression tests in cylindrical specimens were carried out at different temperatures and strain rates; the resulting data were used to determine the parameters of a modified Johnson-Cook constitutive equation, which enabled the prediction of temperature as a function of plastic strain [16].
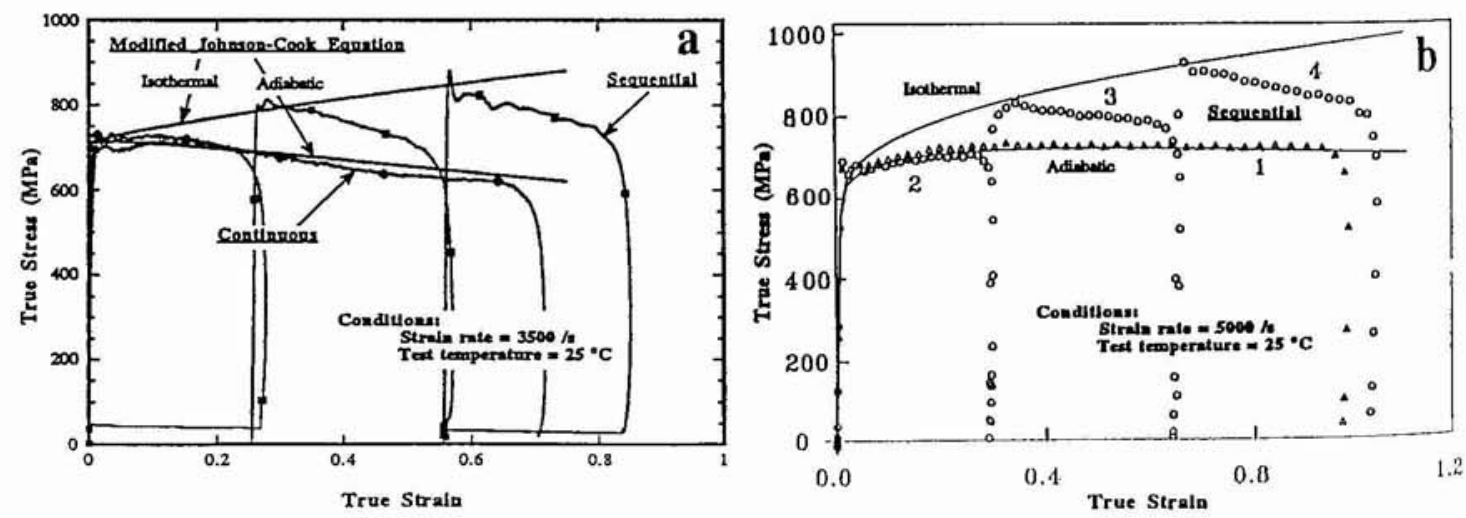

Figure 1 Continuous, sequential (isothermal) and adiabatic stress strain response for: (a) Ta. (b) Ta-1 wt. \% W (TD). 
The use of interrupted tests in the Hopkinson bar, as developed by Nemat-Nasser et al [24], enabled the establishment of the isothermal curve. This is illustrated in Figure 1 for tantalum and tantalum 1 wt.\% W (TD). The origin of the second and third tests was translated so that the strain is additive. The specimen was allowed to cool down prior to the second and third tests. The stress-strain curves show the hardening that is masked by thermal softening in the single test. The envelope of the sequential tests defines an isothermal curve, which diverges significantly from the adiabatic curve. Adiabatic deformation yields softening beyond the strain of 0.1 for tantalum. Typical microstructures obtained during dynamic compression tests are shown in Figure 2 for tantalum $2.5 \mathrm{wt}$. \% W (TD) alloy. These deformation substructures are characterized by a very high dislocation density cell structure and dislocation loops. These loops are probably generated by the collapse of vacancy disks. The strain-rate dependence of the flow stress was determined from the results shown in Figure 3(a). The results of tests carried out at 25,325 , and $525^{\circ} \mathrm{C}$ are compared with earlier results by Mitchell and Spitzig [11] and Hoge and Mukherjee [13].
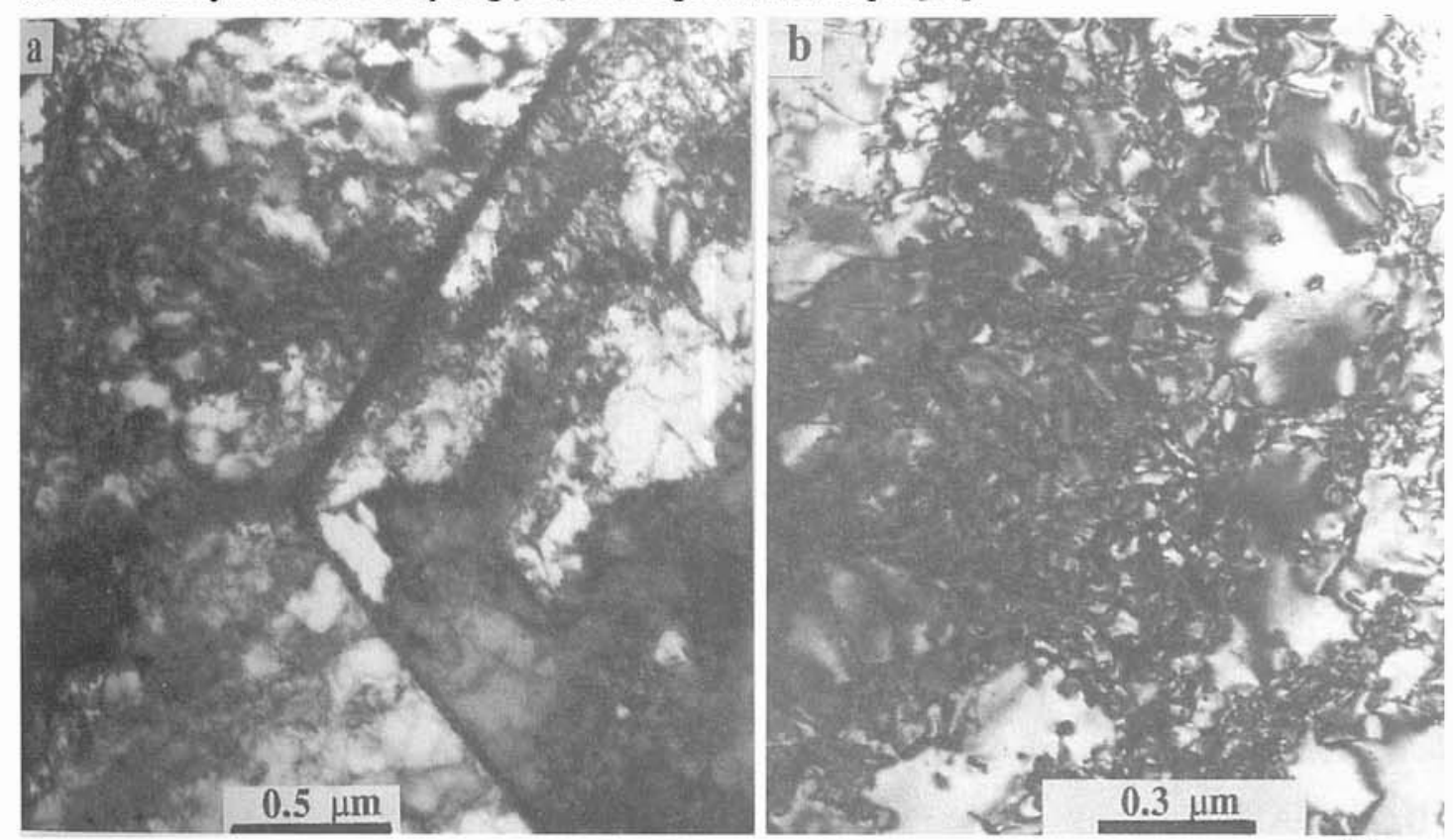

Figure 2. (a) Dislocation morphology in Ta-2.5 wt. \% W (TD) deformed to a strain of 0.365 at a strain rate of $2 \times 10^{3-1}$ (b) details of dislocation cell structures showing dislocation loops.

\subsection{Dynamic Shear Tests}

The objective of these experiments was to probe the initiation of instability in the deformation or shear region. Figure 3(b) shows the shear stress vs. displacement curves for Ta obtained for four different prescribed displacements. The curves show a plateau at a shear stress level of $500 \mathrm{MPa}$ and a sharp increase when the prescribed displacement is reached, because a stopper ring was used to limit the displacement. Figure 4(a-c) shows the typical evolution of the microstructures along the shear localization regions for displacements, $\delta=0.3 \mathrm{~mm}, \delta=1.0 \mathrm{~mm}$, and $\delta=1.4 \mathrm{~mm}$, which correspond to shear strains $\gamma=1.25, \gamma=$ 4.0 , and and $\gamma=5.5$. The shear strains were estimated by two methods which provided similar results: by dividing the displacement by an approximate shear localization thickness, $t$, and by measuring the deflection angle $\alpha$, of the shear markings. The first method was also applied to estimate the microshear strain in each of the TEM discs. As shown, plastic deformation was observed to be strongly inhomogeneous, with some grains showing profuse slip markings, and others appearing to be essentially strain-free. The amount of shear also was observed to vary along the length of the shear localization region. This inhomogeneity manifests itself in differences in the residual microhardnesses, as reported elsewhere [16]. These differences are due to stress/strain concentrations at the sharp corners, considerable variations in the band thickness, and considerable differences in the size of the individual grains, as can be seen in Figure 4. These results indicate that fluctuations in shear strain occur along the length of the shear localization region; the shear strain values given in Figure 4 are only average values. 

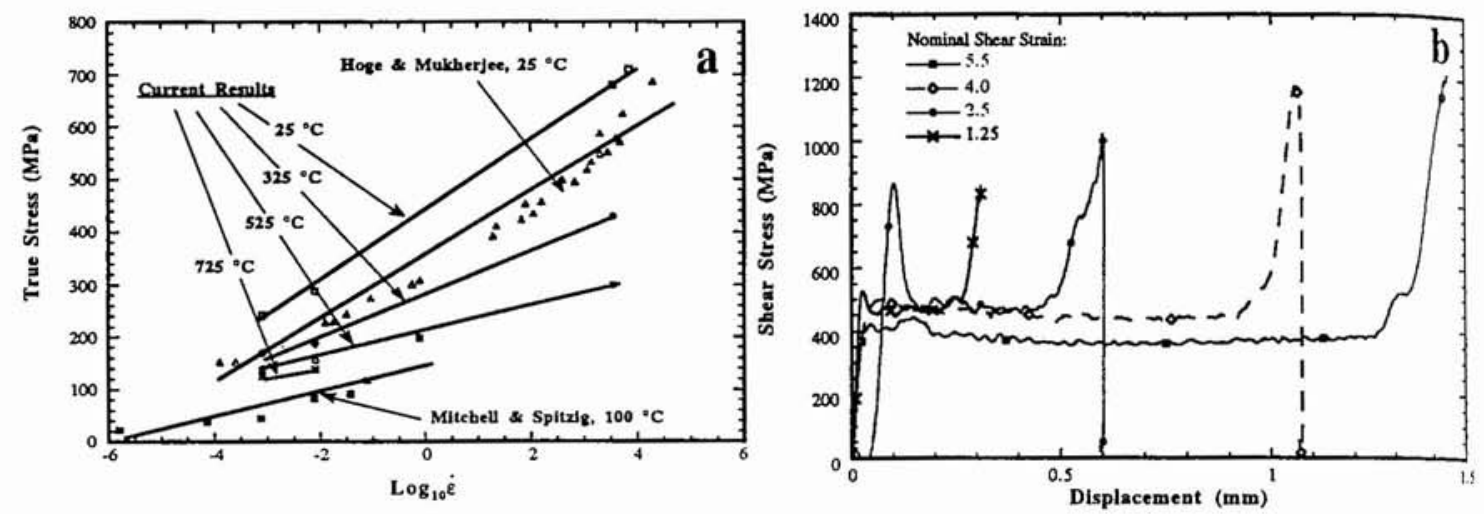

Figure 3. (a) Strain-rate dependence of flow stress for Ta; (b) Shear stress vs. shear displacement for Ta hat-shaped specimens.
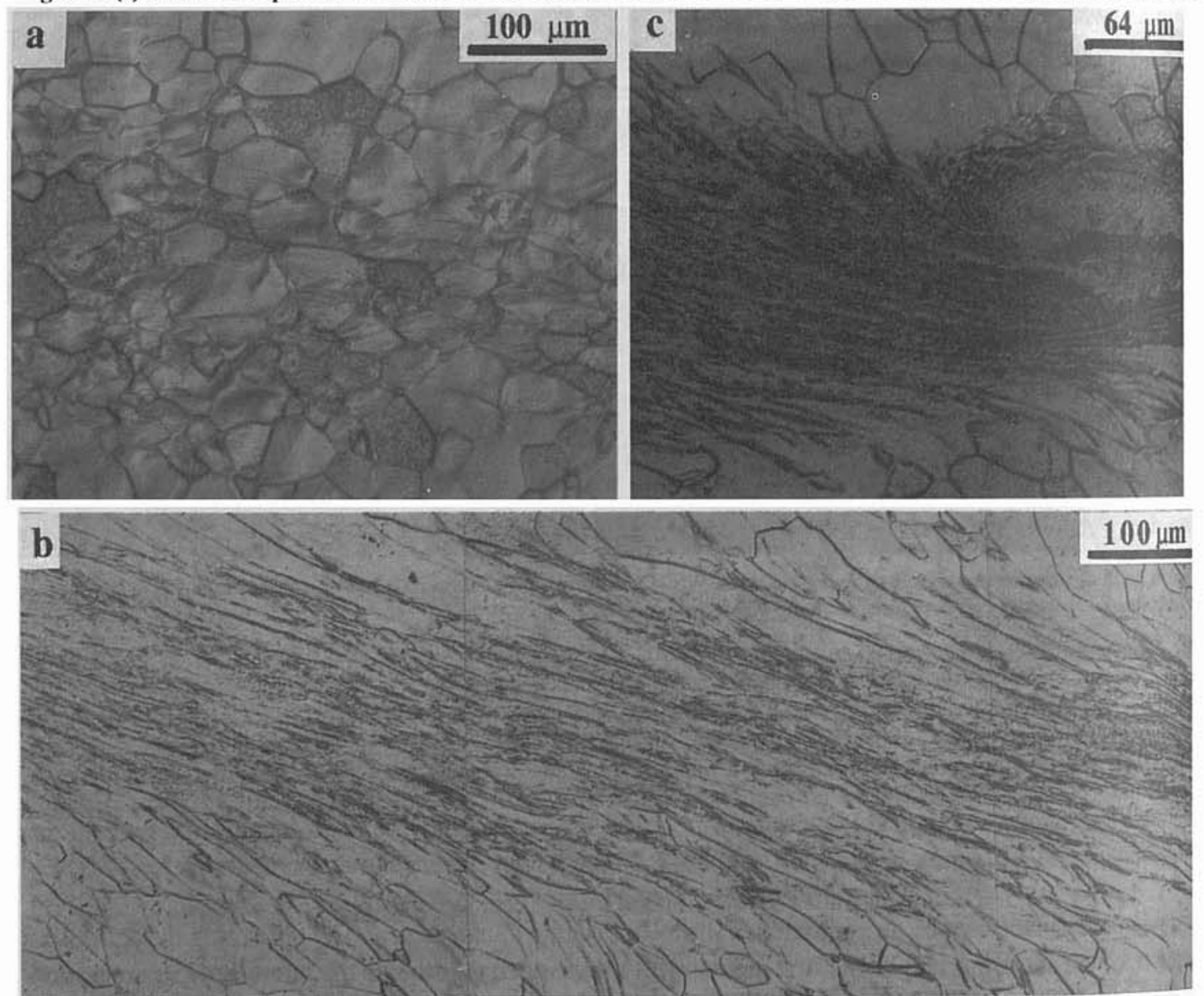

Figure 4. Details of microstructure within the regions of shear localization: (a) $\gamma=1.25$, (b) $\gamma=4.0$, (c) $\gamma=5.5$.

\subsection{Evolution of Microstructure}

The microstructures observed in the hat-shaped specimens are in good agreement with those observed in disk-shaped specimens [16]. These microstructures generated at high-strain rates progress from highly dislocated grains to lath cells, to subgrains, and, finally, to small grains as the shear strain increases. At shear strains above 2.5 , the region of shear localization is characterized by the formation of elongated lath cells as shown in Figures 5(a and b). 

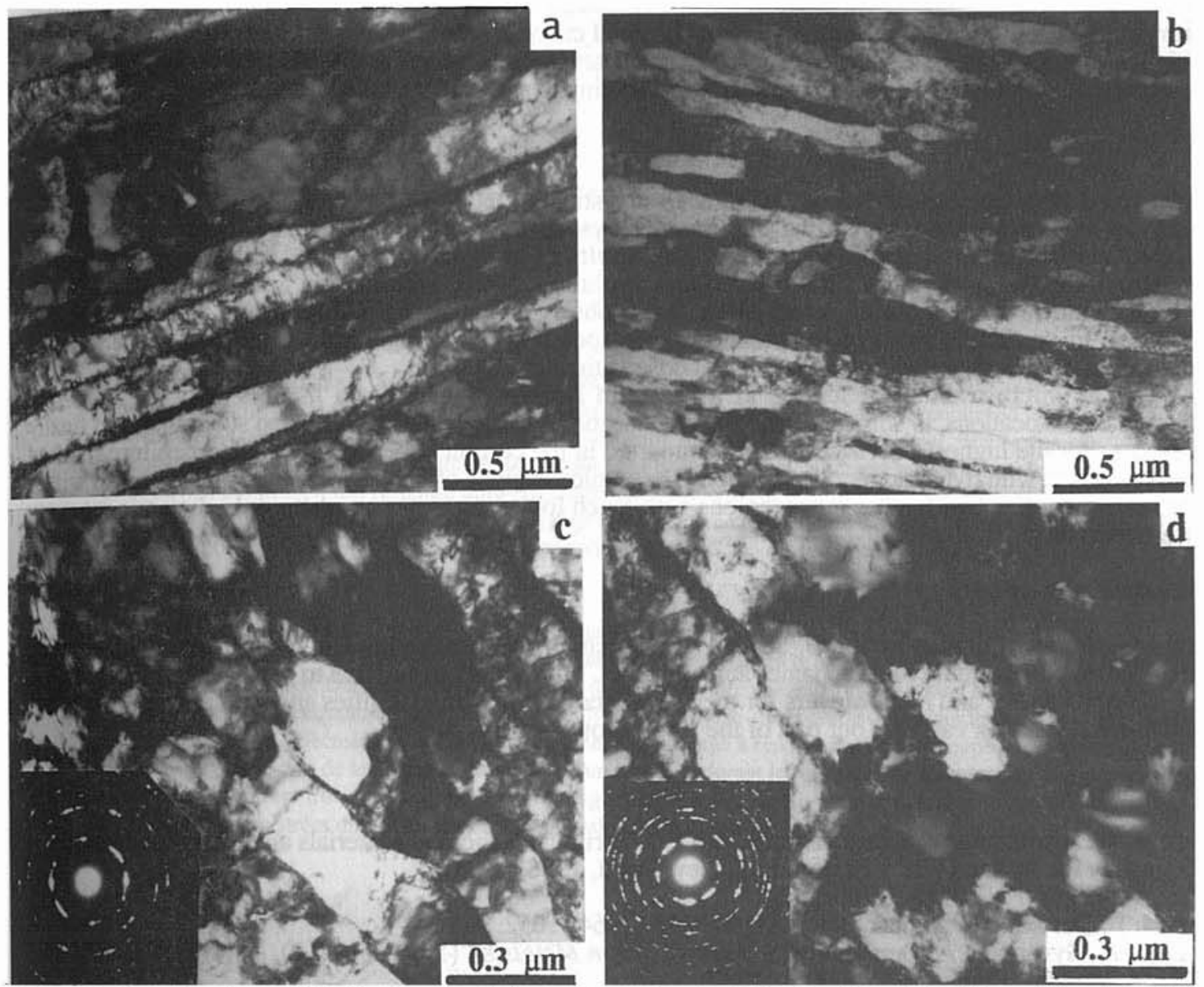

Figure 5. Typical regions within the shear bands in tantalum showing lath cells: (a) $\gamma=2.5$, (b) $\gamma=5.5$, and the first stages of dynamic recrystallization for $\gamma=2.5$.

As the plastic shear strain is increased to 4 and 5.5 , the dislocations tend to form better and better defined cells, which progressively become subgrains. The higher strains are accommodated by a mechanism which involves refinement of the width and length of the elongated lath cells and considerable increase in the dislocation density and substructure of each cell. In some cases, they form along different orientations, while in other cases they are elongated along one orientation. These features are similar to the ones observed by Mgbokwere et al [25] for an AISI 4340 steel. It is proposed that these subgrains are formed by a dynamic recovery mechanism, aided by the thermal excursion that results from the conversion of plastic work into heat.

Careful observations of many specimens showed that some regions underwent extensive dynamic recovery, and others the early stages of dynamic recrystallization, Figs. 5(c and d). This is explained by: (a) the plastic shear strain not being uniform along the length of the shear localization region, (b) the plastic strain varying from grain to grain, (c) certain microregions being able to experience much higher deformations than the average, and (d) considerable difference in the size of individual grains. These factors are typically shown in Figs. 4 and 5. Dynamic recrystallization has been proposed by Muir et al [26] and Gurewitch et al [15] to play an important role in shaped-charge deformation. Indeed, they have characterized recovered specimens from jets and slags and concluded that dynamic recrystallization occurred during jet elongation.

\subsection{Temperature Rise Predictions}

The methodology for the prediction of the temperature rise as a function of the plastic strain and strain rate is reported elsewhere [16]. It was observed that the strain rate within the region of shear localization in the hatshaped specimens is of the order of $4 \times 10^{4} \mathrm{~s}^{-1}$. The reported results show that for the highest average shear strain imparted to the hat-shaped specimens in tantalum $(\gamma=5.5)$ the temperature predicted by the modified 
Johnson-Cook model was of the order of $800^{\circ} \mathrm{K}$. Although this value is low for the observation of dynamic recrystallization, this value is consistent with observed microstructures if one takes into account that this is only the average value of regions with much lower shear strains (experiencing dynamic recovery) alternating with regions with much higher shear strains (experiencing dynamic recrystallization).

\section{CONCLUSIONS}

Two types of tests were carried out in order to investigate the high-strain, high-strain-rate deformation behavior of tantalum and tantalum-tungsten based alloys: dynamic compression tests in cylindrical and diskshaped specimens and dynamic shear tests. The results of these tests were used to develop constitutive equations for the prediction of the temperature evolution during deformation and for the study of the microstructure evolution during deformation. It was observed that a modified Johnson-Cook equation was effective in predicting average temperatures corresponding to average strains and that these average predictions are consistent with microstructural observations.

The microstructure generated at high strain rates evolves from a high density of uniformly distributed dislocations, to slip bands and then intersections, to elongated lath cells, to subgrains, and finally tograins. For the highest microshear strains imparted in the current experiments, the temperature reached was consistent with dynamic recrystallization. These microregions of highest microstrains alternated within the same shear band with other microregions with much lower microstrains where only dynamic recovery was observed.

\section{Acknowledgements}

This research was funded by the U. S. Army Research Office through the University Research Initiative Program and the Institute for Mechanics and Materials. The authors would like to express their appreciation to S. Nemat-Nasser and M.A. Meyers for the use of laboratory testing facilities and stimulating discussions and to J.B. Isaacs for carrying out part of the Hopkinson bar experiments.

\section{References}

1. R. W. Armstrong, V. Ramachandran, and F. J. Zerilli, Advances in Materials and their Applications, ed. P. Rama Rao (Wiley Eastern Ltd., New Dehli, 1988), p. 201.

2. A. Seeger, Phil. Mag. 1(1956) 651.

3. J. E. Dom and S. Rajnak, Trans. AIME 230 (1964) 1052.

4. L. A. Gypen and A. Deruyettere, J. Less-Common Metals 86 (1982) 219-240.

5. M. Werner, Phys. Stat. Sol. 104 (1987) 63-78.

6. H. Koizumi, H. O. K. Kirchner, and T. Suzuki, Acta Met. Mater. 41(1993) 3483-93.

7. F. J. Zerilli and R. W. Armstrong, J. Appl. Phys. 61 (1986), (5) 1816-25.

8. F. J. Zerilli and R. W. Armstrong, J. Appl. Phys. 68 (1990), (4) 1580-91.

9. J. H. Bechtold, Acta Met. 3 (1955) 249.

10. A. Gilbert, D. Hull, W. S. Owen, and C. N. Red, J. Less-Common Metals 4 (1962) 399.

11. T. E. Mitchell and W. A. Spitzig, Acta Met. 13 (1965) 1169.

12. B. L. Mordike and G. Rudolf, J. Mat. Sci. 2 (1967) 332.

13. K. G. Hoge and A. K. Mukherjee, J. Mat. Sci. 12 (1977) 1666.

14. D. Lassila and G. T. Gray, J. de Physique IV (Colloque) 1 (1991) (C3) 19-26.

15. A. C. Gurevitch, L. E. Murr, H. K. Singh, C.S. Nion, A. H. Advani, D. Marual, and L. Zerron, Matls. Charact. 30 (1993) 201-216.

16. M. Meyers, Y.J. Chen, F.D.S. Marquis, and D.S. Kim, High-Strain, High-Strain-Rate Behavior of Tantalum, Metallurgical and Materials Transactions 26A (1995) 2493-2501.

17. C. Feng and P. Kumar, J. of Metals 41 (1989) 40-45.

18. J. B. Clark, R. K. Garrett, Jr., T. L. Jungling, R. A. Vandermeer, and C. L. Vold, Met Trans. 22A (1991) 2039-2048.

19. J. B. Clark, R. K. Garrett, T. L. Jungling, and R. I. Asfahani, Met. Trans. 23A (1992) 2183 -2191.

20. L. W. Meyer and S. Manwaring, Metallurgical Applications of Shock-Wave and High-Strain-Rate Phenomena, eds. L. E. Murr, K. P. Standhammer, and M. A. Meyers (M. Dekkor, NY, 1986) p. 657.

21. M. A. Meyers, G. Subhesh, B. K. Kad, and L. Prasad, Mech. of Matls. 17 (1994) 175-199.

22. U. R. Andrade, M. A. Meyers, K. S. Vecchio, and A. H. Chokshi, Acta Met. Mater. 42 (1994) 318395.

23. S. Nemat-Nasser, J. B. Isaacs and J. E. Starrett, Proc. Roy. Soc. A20 (1991) 371 - 391.

24. S. Nemat-Nasser, Y.-F. Li, and J. B. Isaacs, Mech. of Matls 17 (1994) 111-134.

25. C. O. Mgbokwere, S. R. Nutt, and J. Duffy, Mech. of Matls. 17 (1994) 97-110.

26. L. E. Murr. C.S. Niou. and C.. Feng. Scrinta Met. Mat. 31 (1994) (3) 297-302 